\title{
Analyzing Predictive Factors Associated with the Variable Rates of Prevalence of Post-Traumatic Stress Disorder among National Guard/Reserve Soldiers Compared to Active Duty Soldiers: A Pilot Study
}

\author{
Shannon M. Philipps', Murray R. Berkowitz ${ }^{2 *}$ \\ ${ }^{1}$ Department of Neurology, Medical College of Georgia, Augusta University, Augusta, Georgia, USA \\ ${ }^{2}$ Preventive and Community-Based Medicine, Department of Osteopathic Medicine, Philadelphia College of Osteopathic \\ Medicine, Georgia Campus, Suwanee, Georgia, USA \\ Email: shaphillips1@augusta.edu, *murraybe@pcom.edu
}

How to cite this paper: Philipps, S. M., \& Berkowitz, M. R. (2019). Analyzing Predictive Factors Associated with the Variable Rates of Prevalence of Post-Traumatic Stress Disorder among National Guard/Reserve Soldiers Compared to Active Duty Soldiers: A Pilot Study. Psychology, 10, 2224-2246. https://doi.org/10.4236/psych.2019.1016141

Received: October 12, 2019

Accepted: December 27, 2019

Published: December 30, 2019

Copyright $\odot 2019$ by author(s) and Scientific Research Publishing Inc. This work is licensed under the Creative Commons Attribution International License (CC BY 4.0). http://creativecommons.org/licenses/by/4.0/

\section{Open Access}

\begin{abstract}
Research Aim: The aim for this study was to better understand the higher post-deployment prevalence of PTSD among National Guard/Reserve Soldiers compared to Active Duty Soldiers by analyzing the possible predictive factors associated with the variable rates. Since September 11th, 2001, the United States Army has deployed a significantly larger percentage of National Guard and Reserve forces to combat zones in support of Operation Enduring Freedom and Operation Iraqi Freedom. The United States Office of Veterans Affairs has reported increased suicide rates and suicide risk for Post-traumatic Stress Disorder (PTSD) for Soldiers deployed in support of these conflicts in particular. Few studies have assessed the relationship between military component (Active Duty vs. Reserve Component) and PTSD prevalence and risk factors but many of the studies that exist have reported higher rates in Reserve Component Soldiers as compared to Active Duty Soldiers. This study identifies and discusses possible implications for these specific vulnerabilities. Research Methods: The Deployment Risk and Resilience Inventory were used to assess the service members' trauma-related experiences. The Connor-Davidson Resilience Scale was used to assess resiliency as a pre-existent factor inherent to the individual. The Treatment Reactions Scale was used to assess stigma for PTSD treatment. Statistical analysis of variance was performed using Graphpad Prism 6 Software to find if there were any statistical differences between prevalence rates. Linear regression analysis was used to determine correlations between predictive factors and PTSD
\end{abstract}


within each component. Trial Registration: Philadelphia College of Osteopathic Medicine Institutional Review Board Protocol \#H15-034X (April 13, 2015).

\section{Keywords}

Post-Traumatic Stress Disorder, PTSD, Resilience

\section{Introduction}

As America withdraws forces from the War on Terror and more veterans return to the homeland every month, we begin to observe the aftermath that combat exposure has on our Soldiers. The number of veteran suicides has been increasing yearly since 2001 (Kemp \& Boassarte, 2012) and Afghanistan and Iraq war zone veterans with mental disorders such as Post-Traumatic Stress Disorder (PTSD) are at increased risk for suicidal thoughts and acts (Kang \& Bullman, 2008). Since 2008 deployment time and combat zone exposure time have increased for veterans (Baiocchi, 2013), and increasing Soldier combat time increases their likelihood of being exposed to mental disorders like PTSD (Shiromani et al., 2009). As more soldiers who have spent greater amounts of time in combat zones are returning home, the rising prevalence of PTSD is a major concern in the United States military (Hoge et al., 2004).

The aim of this study was to better understand the higher post-deployment prevalence of PTSD among National Guard/Reserve Soldiers compared to Active Duty Soldiers by analyzing the possible predictive factors associated with the variable rates.

Several research questions were considered. What association do the following factors-concern about family life and disruption, unit cohesion, resiliency, social support, age, preparation, perceived threat, and stigma for seeking psychological help-have on the prevalence of Post-Traumatic Stress Disorder among NG/Reservists compared to Active Duty Soldiers that deployed during OIF and OEF? Also, do the observed differences provide implications for why the prevalence of PTSD is often reported to be higher among NG/Reservists than Active Duty Soldiers? The hypothesis for this study is that self-reported post-deployment PTSD or PTSD-related behavior is reported higher among NG/R Soldiers than Active Duty Soldiers (Mansfield et al., 2011; Milliken et al., 2007; Pietrzak et al., 2010; Waysman, 2001). Further, is higher self-reported prevalence of PTSD among NG/R Soldiers compared to Active Duty Soldiers positively correlated with predictive factors associated with PTSD?

\section{Literature Review}

\subsection{Post-Traumatic Stress Disorder Defined}

Post-Traumatic Stress Disorder is a mental illness that can arise in anyone as a 
result of experiencing a lethal or traumatic event (Hoge et al., 2004). It was first regarded as a psychiatric disorder in 1980 when it was added to the third edition of the Diagnostic and Statistical Manual of Mental Disorders 3rd ed. (DSM-III) (Friedman, 2013). DSM-III distinguished PTSD from other mental disorders by stating its etiology arose from an external traumatic event rather than a congenital individual disorder (Friedman, 2013). The psychological aftermath of exposure to the traumatic event(s) and the development of specific characteristic symptoms are essential key features of PTSD. In general, these include exacerbated feelings of intense fear, helplessness, anhedonia, and restlessness (Campbell, 2009). The DSM-III classified PTSD as an Anxiety Disorder; however, the latest Diagnostic and Statistical Manual of Mental Disorders 5th ed. (DSM-V, 2013) criteria classify the disease as a Trauma-and Stress-Related Disorder. This means disease onset must have a temporal relationship with exposure to a traumatic event (DSM-V, 2013). The DSM-V has eight criteria for the diagnosis of PTSD. Criterion A is necessary for any diagnosis of PTSD while criteria B-E involve the psychological and behavioral related symptoms to Criterion A.

Identifying exposure to a "traumatic event", Criterion A, is the key to understanding the clinical diagnosis for PTSD. Currently, DSM-V defines a traumatic event as "exposure to actual or threatened death, serious injury, or sexual violence (DSM-V, 2013)". Exposure to traumatic events can occur in multiple variations including the following: direct experience to trauma, witnessing others experience trauma, learning about events that happened to close relatives or acquaintances, or experiencing repeated exposure to apathetic circumstances of traumatic events. The features of the event predict the development and severity of the disorder (DSM-V, 2013).

Involuntary recollection of events (Criterion B) that dominate the psychological state of mind is the most common symptom of PTSD. Event recollection occurs in multiple forms including memories, dreams, flashbacks, or psychological or physiological reactions to cues that mirror the traumatic exposure (DSM-V, 2013). Criterion C involves persistent avoidance of potential stimuli that could be associated with the traumatic event (DSM-V, 2013). In extreme cases, agoraphobia persists because the PTSD victim is afraid of confronting potential stress triggers of the event (Friedman, 2013). Negative cognitions and mood depressions fall under Criterion D; these include erroneous conclusions about the PTSD victims themselves, others, and the world around them (Friedman, 2013). Other symptoms of Criterion D include self-blame, event amnesia, diminished interest in previously enjoyed activities, isolation from the company of others, and inability to experience positive emotion (DSM-V, 2013). Criterion $\mathrm{E}$ is the final behavioral change related criterion and involves alterations in arousal or reactivity. These symptoms are more closely related to those of common anxiety disorders (Friedman, 2013). Indicators include irritability, recklessness, sleep disorders, hypervigilance, and self-destructive behavior (DSM-V, 2013). 
The final three criteria of the DSM-5 PTSD checklist involve technicalities for the aforementioned symptoms. Criterion $\mathrm{F}$ states that duration of disturbance (C-E) must be present for at least one month, and G states that the disturbance must cause distress or impairment in social or occupational activities of daily living. Finally, Criterion $\mathrm{H}$ requires that the disturbance is not attributable to physiological effects of external substances (DSM-V, 2013). Though the criteria for diagnosis of PTSD are long and explicit, the prevalence is still an alarming rate particularly among combat veterans.

\subsection{Combat Veterans and Risk for PTSD}

Combat veterans are at the highest risk of exposure to all the aforementioned types of traumatic events in Criterion A, therefore putting them at the greatest risk for PTSD (Richardson et al., 2010; Shiromani et al., 2009). Identifying risk factors may provide an understanding for why some people exposed to traumatic events develop PTSD and others do not. Several studies have correlated internal and external factors that may increase risks for PTSD.

Generally, risk factors for PTSD are grouped into three categories: factors inherent to the individual that experienced the traumatic event, factors related to the traumatic event, and factors that occurred after the event (Shiromani et al., 2009). Factors inherent to the individual are characteristics that the individual possesses prior to exposure to the traumatic event. This can include prior traumatic experiences, existing psychological disorders, or traits associated with an individual's character such as resiliency. When studying combat-related trauma, resilience seems to be the most relevant measure.

Resilience plays a role in decreasing the negative effects of trauma, especially in military populations (Pietrzak et al., 2010). It is important to note that resiliency is not simply the opposite of a risk factor but rather an intricate and inherent process that leads to protection from the disease. It is an attribute inherent to the individual and thus encompasses both psychological and biological traits that one may possess and use as a mechanism to deter the pathology of PTSD (Milliken et al., 2007). Additionally, resilience can be a risk buffer by mediating the effect of other predictors of PTSD such as social support or unit cohesion (Pietrzak et al., 2010). The protective effect of resilience has been recorded in veterans of the post-911 era. Generally, a higher resilience rating is associated with lower PTSD symptoms (Mansfield et al., 2011; Pietrzak et al., 2010; Pietrzak \& Southwick, 2011).

When assessing predictive factors for PTSD among combat veterans, factors related to the trauma-causing event are conditions of the deployment or combat experience. A Soldier's combat experiences during deployment involve direct exposure to traumatic events that pose immediate danger to physical health or survival (Renshaw, 2011). There is a known effect between combat experiences and the development of PTSD but it is an indirect association mediated by perceived threat (Renshaw, 2011). A Soldier's perceived threat, or concern about safety and survival, has reaped attention from multiple studies as being more di- 
rectly associated with PTSD than actual combat experience (Iversen et al., 2008; James et al., 2013; King et al., 1995; Renshaw, 2011). Individuals with the perception that their safety or survival is endangered have higher risks for PTSD (Ozer et al., 2008). Additionally, a Soldier's sense of preparedness prior to battle can moderate the relationship between perceived threat and combat experiences. Soldiers that have higher levels of preparedness perceive threat more closely associated with combat exposure, while those that feel less prepared for deployment perceive high threat regardless of combat experience (Mansfield et al., 2011). Combat experience, perceived threat, and preparedness are all predictive factors that are interrelated.

Predictive factors for PTSD during combat also involve the personal life of a soldier. Concern about family life or disruption and social support during deployment both fall within this realm. Research shows that veterans who screen positive for PTSD report less social functioning as well as less social support during deployments than those that screen negative (Tsai et al., 2012). They are also more likely to have stress about family life at home when screened positive for PTSD (Tsai et al., 2012).

The final category of predictive factors for PTSD is the factors that occur after the trauma. This includes a Soldier's ability and willingness to seek help for PTSD related symptoms as well as post-deployment social support. Post-trauma social support is a factor that occurs after the trauma that may be a protector for PTSD. Individuals that perceive themselves as having less social support after combat are linked to more symptoms of PTSD. Similarly, those with more support have less symptoms associated with criteria for PTSD (James et al., 2013; Ozer et al., 2008; Renshaw, 2011). Identifying and controlling for these factors is important to reducing PTSD Prevalence and its effect on society.

\section{Methods}

\subsection{Survey Procedure and Population Sample}

The Philadelphia College of Osteopathic Medicine Institution Review Board approved this project. The sampling population consisted of 11 OEF/OIF Army veterans. 50 soldiers were emailed for recruitment in the study. Of those veterans who received the email, 26 agreed to participate, corresponding to a $52 \%$ response rate. Of these 26 only 11 completely finished the survey. Surveymonkey was used to distribute the survey electronically. The 15 incomplete responses were excluded. Overall this resulted in a $22 \%$ response rate. Participants were divided evenly between Active Duty and National Guard/Reserve components with 6 (55\%) AD and 5 (45\%) NG/R.

All participants in the sample provided information on military career and status. All participants reported they were deployed after September $11^{\text {th }}, 2001$ and all of the participants were male. One participant reported a prior diagnosis of PTSD. The sample consisted of both noncommissioned officers and commissioned officers. There were 8 noncommissioned officers total (73\%) and 3 com- 
missioned officers total (27\%), 2 of which were NG/R. The current ranks of all the soldiers ranged from Specialist (SPC/E4) to Colonel (COL/O6). The ranks at deployment ranged from Private First class (PFC/E3) to Lieutenant colonel (LTC/O5). The current ranks of AD ranged from Sergeant (SGT/E5) to LTC/O5 and the ranks at deployments of $\mathrm{AD}$ ranged from SGT/E5 to Major (MAJ/O4). The current ranks of NG/R ranged from SPC/E4 to COL/O6. The ranks of NG/R at deployment ranged from $\mathrm{PFC} / \mathrm{E} 3$ to $\mathrm{LTC} / \mathrm{O} 5$.

\subsection{Measures}

Multiple surveys were used to determine the association between the prevalence of PTSD in the population with the following predictive factors: concern about family life and disruption, unit cohesion, resiliency, social support, age, preparation, perceived threat, and stigma for seeking psychological help.

The PTSD Checklist for DSM-V (PCL-5) was used to screen Soldiers for PTSD. Although a personal interview with a clinician is the Gold Standard for diagnosing PTSD, the PTSD Checklist is a consistently reliable alternative when this option is unavailable (Bliese et al., 2008; Keen et al., 2008). This is a 17-item survey with categories of questions corresponding to symptoms for PTSD (DSM-V, 2013). Participants respond to each question using a 5-point response scale ranging from $1=$ not at all to $5=$ extremely $(\mathrm{DSM}-\mathrm{V}, 2013)$.

The Deployment Risk and Resilience Inventory (DRRI) were used to assess the service members' trauma-related experiences (King et al., 2006; Vogt \& King, 2012). Seven scales from the DRRI was used in this study: combat experiences, perceived threat, preparedness, deployment (Vogt \& King, 2012) social support, unit cohesion, concern about family life and disruption, and post-deployment social support (King et al., 2006; Vogt \& King, 2012). All items in the scale show strong reliability and validity with a coefficient alpha of at least 0.82 for all (King et al., 2006; Vogt \& King, 2012).

\subsubsection{Combat Experiences}

Combat experiences are events that are related to warfare, such as firing a weapon or being fired upon, engaging the enemy or being engaged by the enemy, or going on combat patrols. This is a 15-item scale with a 6-point Likert response format based on how often a service member experienced combat situations during deployment $(1=$ Never, $6=$ Daily or almost daily $)($ Vogt $\&$ King, 2012).

\subsubsection{Perceived Threat}

Perceived threat quantifies the extent to which a service member feels he is in danger, particularly in response to experiencing a war zone (Vogt \& King, 2012). This is a 15 -item scale with a 5-point Likert response format $(1=$ Strongly disagree, 5 = Strongly agree) (Vogt \& King, 2012).

\subsubsection{Preparedness}

Preparedness is the extent to which an individual feels he is prepared for deployment. This includes having the proper equipment, supplies, and training to 
perform his duty. Additionally, this includes the extent to which the veteran feels he was sufficiently informed in what to expect in his role during deployment (Vogt \& King, 2012). This is a 10-item scale with a 5-point Likert response format $(1=$ Strongly disagree, 5 = Strongly agree) (Vogt \& King, 2012).

\subsubsection{Deployment Support from Family and Friends}

This measure quantifies the extent to which a service member feels emotional support and assistance from family and friends back home during a deployment. This is how emotionally well cared for by family and friends a service member feels while on deployment (Vogt \& King, 2012). This is an 8-item scale with a 5-point Likert response format $(1=$ Strongly disagree, $5=$ Strongly agree $)($ Vogt \& King, 2012).

\subsubsection{Unit Social Support}

Unit social support is the extent to which a service member perceives encouragement from his military unit. This includes the extent to which the Soldier feels camaraderie with his fellow Soldiers and appreciation from his unit leaders (Vogt \& King, 2012). This is a 12-item scale with a 5-point Likert response format $(1$ = Strongly disagree, 5 = Strongly agree $)($ Vogt \& King, 2012).

\subsubsection{Concerns about Family Life and Disruption}

Concerns about family life and disruption measure how worried a Soldier is that the deployment may affect other domains of his home life. This primarily involves family concerns or damaging relationships with spouses and/or children. This is a 15-item scale with a 4-point Likert response format $(1=$ not at all; $4=$ a great deal; 0 $=$ not applicable). When scoring, not applicable is coded the same as not at all.

\subsubsection{Post-Deployment Social Support}

Post-deployment social support is the extent to which a Soldier's family and friends provide emotional support and assistance after the Soldier returns to the homeland. It refers to the extent that soldier feels he has received emotional and tangible aid to grow accustomed and be successful in life after deployment (Vogt \& King, 2012). This is a 10-item scale with a 5-point Likert response format $(1=$ Strongly disagree, 5 = Strongly agree) (Vogt \& King, 2012).

The Connor-Davidson Resilience Scale (CD-RISC) was used to assess resiliency as a pre-existent factor inherent to the individual. Resiliency is an individual's ability to recover from hardship and is thus a type of stress coping mechanism that can modify an individual's risks for psychological disorders like PTSD (Connor Jonathan, 2003). The CD-RISC shows strong reliability and validity with a correlational coefficient of 0.87 (Connor Jonathan, 2003). CD-RISC is a 25 -item scale with a 4 -point Likert response format $(0=$ not true at all; $4=$ true nearly all the time) (Connor Jonathan, 2003).

The Treatment Reactions Scale (TRS) was used to assess stigma for PTSD treatment. The TRS was developed to assess stigma amongst combat Soldiers specifically (Reger et al., 2013). It focuses on five content areas: embarrassment/shame for seeking treatment, career impact for seeking treatment, per- 
ceived debasement for receiving treatment, willingness to recommend treatment, and confidence in belief or efficacy of treatment (Reger et al., 2013). The TRS shows strong reliability with an overall alpha coefficient of 0.95 and a range of $0.81-0.89$ for each subset (Reger et al., 2013). The survey format is 31 items with a 5-point Liker response format ( $1=$ strongly disagee, $5=$ strongly agree) (Reger et al., 2013). The TRS also has multiple subscales that can measure various aspects of reactions to psychological treatment. In addition to the total score, the Embarrassment/Shame subscale was used to assess shame for seeking a particular treatment. This involved scoring items 2, 5, 22, 24, and 29 separately.

Linear regression analysis was performed for each military component separately to determine if there were correlations between predictive factors and PTSD symptoms. AD linear regression tests were performed first, followed by NG/R. For each component, the first round of regression analysis involved comparing PCL scores with CD-RISC scores, TRS Total scores, and the scores from the TRS Shame subset. The second round of regression analysis involved comparing PCL scores with the scores from the DRRI-2 subscales Combat Experiences, Perceived Threat, and Training. The third and final round of linear regression analysis compared PCL scores with the scores from the remaining DRRI-E subscales Deployment Social Support, Unit Cohesion, Concern about Family Life and Disruption, and Post-deployment Social Support. 95\% confidence intervals were used for all regression analysis with $p<0.05$.

\subsection{Data Analysis Method}

The aforementioned measures were used to find the self-reported prevalence rates of PTSD in the sample. Statistical analysis of variance was performed using Graphpad Prism 6 Software to find if there were any statistical differences between prevalence rates. Descriptive statistics for all PTSD predictive factors and PCL-5 scores were then calculated separately between each component. Finally, simple linear regression analysis was used to determine correlations between predictive factors and PTSD within each component. 95\% confidence intervals were used for all tests with $p<0.05$. All scores were recorded in an excel spreadsheet. Participants were randomly assigned numbers as their surveys came in in order to organize their results. No personal identifiers were used as Surveymonkey is completely anonymous and cannot be traced back to an individual.

\section{Results}

There were no significant differences found between component and length of deployment, current age, age at deployment, time in service, and time in service at start of deployment (see Table 1). Therefore none of these demographics are confounders in the current study. There was a significant difference between the number of times each component deployed. This was expected as every NG/R surveyed only reported deploying once since September 11, 2001. Demographics by component ( $\mathrm{AD}$ vs. $\mathrm{NG/R}$ ), as well as for all study participants are displayed 
in Table 2 and Table 3, respectively. Table 4 displays the raw scores for each participant. Table 5 displays averages and their standard deviations for all scores in every survey for $\mathrm{AD}$ and $\mathrm{NG} / \mathrm{R}$. The table also shows $t$ statistics and R-squared values reflecting results of score comparisons between the two components. The table shows that there were no significant differences in scores for any of the predictive factors or PTSD symptoms in this analysis.

Table 1. Population demographics.

\begin{tabular}{cccccc}
\hline & $\begin{array}{c}\text { Active Duty } \\
(\mathrm{n}=6)\end{array}$ & $\begin{array}{c}\text { National Guard/Reserve } \\
(\mathrm{n}=5)\end{array}$ & $\begin{array}{c}\text { Both AD and NG/R } \\
(\mathrm{n}=11)\end{array}$ & $t$ & $\begin{array}{c}\text { R-squared } \\
(p<0.05)\end{array}$ \\
\hline $\begin{array}{c}\text { \#Times Deployed } \\
\text { Since 9/11/2001 }\end{array}$ & $\mathrm{X}=2.67, \mathrm{SD}=1.37$ & $\mathrm{X}=1, \mathrm{SD}=0$ & $\mathrm{X}=2.45, \mathrm{SD}=4.34$ & 4.781 & $0.820^{*}$ \\
$\begin{array}{c}\text { Length of Deployment } \\
\text { (month) }\end{array}$ & $\mathrm{X}=11.3, \mathrm{SD}=2.58$ & $\mathrm{X}=11.6, \mathrm{SD}=4.34$ & $\mathrm{X}=11.45, \mathrm{SD}=3.30$ & 0.120 & 0.002 \\
$\begin{array}{c}\text { Current Age } \\
\quad \text { (years) }\end{array}$ & $\mathrm{X}=32.7, \mathrm{SD}=6.25$ & $\mathrm{X}=32.4, \mathrm{SD}=7.43$ & $\mathrm{X}=32.54, \mathrm{SD}=6.45$ & 0.064 & 0.010 \\
$\begin{array}{c}\text { Age at Deployment } \\
\text { (years) }\end{array}$ & $\mathrm{X}=29.0, \mathrm{SD}=4.98$ & $\mathrm{X}=30.4, \mathrm{SD}=13.0$ & $\mathrm{X}=30.60, \mathrm{SD}=8.84$ & 0.227 & 0.051 \\
$\begin{array}{c}\text { Time in Service } \\
\text { (years) }\end{array}$ & $\mathrm{X}=13.5, \mathrm{SD}=4.32$ & $\mathrm{X}=10.8, \mathrm{SD}=10.9$ & $\mathrm{X}=12.27, \mathrm{SD}=7.66$ & 0.521 & \\
$\begin{array}{c}\text { Time in Service at Start } \\
\text { of Deployment (years) }\end{array}$ & $\mathrm{X}=9.17, \mathrm{SD}=4.07$ & $\mathrm{X}=6.20, \mathrm{SD}=11.0$ & $\mathrm{X}=7.81, \mathrm{SD}=7.73$ & 0.568 & 0.061 \\
\hline
\end{tabular}

*Significant Difference.

Table 2. Demographic input data by component.

\begin{tabular}{|c|c|c|c|c|c|c|c|c|c|c|c|}
\hline Participant & Gender & Component & $\begin{array}{c}\text { \#Times } \\
\text { Deployed since } \\
9 / 11\end{array}$ & $\begin{array}{l}\text { Length of } \\
\text { deployment } \\
\text { (months) }\end{array}$ & $\begin{array}{l}\text { Current } \\
\text { Age }\end{array}$ & $\begin{array}{c}\text { Age at } \\
\text { Deployment }\end{array}$ & $\begin{array}{l}\text { Time in } \\
\text { service } \\
\text { (years) }\end{array}$ & $\begin{array}{c}\text { Time in } \\
\text { service at } \\
\text { deployment } \\
\text { (years) }\end{array}$ & Rank & $\begin{array}{c}\text { Rank at } \\
\text { deployment }\end{array}$ & $\begin{array}{c}\text { History } \\
\text { of Mental } \\
\text { Illness }\end{array}$ \\
\hline 1 & male & $\mathrm{AD}$ & 3 & 12 & 28 & 22 & 11 & 2 & SSG/E6 & \multicolumn{2}{|c|}{ SSG/E6 } \\
\hline 2 & male & $\mathrm{AD}$ & 4 & 11 & 33 & 31 & 13 & 11 & SSG/E7 & \multicolumn{2}{|c|}{ SSG/E7 } \\
\hline 3 & male & $\mathrm{AD}$ & 3 & 11 & 32 & 27 & 13 & 8 & SSG/E6 & \multicolumn{2}{|c|}{ SGT/E5 } \\
\hline 4 & male & $\mathrm{AD}$ & 4 & 9 & 33 & 32 & 12 & 11 & SGT/E5 & SGT/E5 & Y, PTSD \\
\hline 5 & male & $\mathrm{AD}$ & 2 & 16 & 44 & 36 & 22 & 14 & LTC/O5 & \multicolumn{2}{|c|}{$\mathrm{MAJ} / \mathrm{O} 4$} \\
\hline 6 & male & $\mathrm{AD}$ & 6 & 9 & 26 & 26 & 10 & 9 & SSG/E7 & \multicolumn{2}{|c|}{ SSG/E7 } \\
\hline Mean & & & 3.666666667 & 11.33333333 & 32.66666667 & 29 & 13.5 & 9.1666666667 & & & \\
\hline SD & & & 1.366260102 & 2.581988897 & 6.250333324 & 4.979959839 & 4.324349662 & 4.070217029 & & & \\
\hline 7 & male & NG/R & 1 & 16 & 25 & 20 & 6 & 1 & SGT/E5 & \multicolumn{2}{|c|}{ SPC/E4 } \\
\hline 8 & male & NG/R & 1 & 11 & 26 & 24 & 4 & 2 & SPC/E4 & \multicolumn{2}{|c|}{$\mathrm{PFC} / \mathrm{E} 3$} \\
\hline 9 & male & NG/R & 1 & 11 & 36 & 33 & 5 & 1 & SGT/E5 & \multicolumn{2}{|c|}{ SGT/E5 } \\
\hline 10 & male & NG/R & 1 & 15 & 32 & 23 & 9 & 1 & $1 \mathrm{LT} / \mathrm{O} 2$ & \multicolumn{2}{|c|}{ SPC/E4 } \\
\hline 11 & male & NG/R & 1 & 5 & 43 & 52 & 30 & 26 & COL/O6 & \multicolumn{2}{|c|}{ LTC/O5 } \\
\hline Mean & & & 1 & 11.6 & 32.4 & 30.4 & 10.8 & 6.2 & & & \\
\hline SD & & & 0 & 4.335896678 & 7.436396977 & 13.01153335 & 10.89495296 & 11.0770032 & & & \\
\hline
\end{tabular}


Table 3. Demographic input data for all participants.

\begin{tabular}{|c|c|c|c|c|c|c|}
\hline Participant & $\begin{array}{c}\text { \#Times } \\
\text { Deployed } \\
\text { since } 9 / 11\end{array}$ & $\begin{array}{l}\text { Length of } \\
\text { deployment } \\
\text { (months) }\end{array}$ & $\begin{array}{c}\text { Current } \\
\text { Age }\end{array}$ & $\begin{array}{c}\text { Age at } \\
\text { Deployment }\end{array}$ & $\begin{array}{l}\text { Time in } \\
\text { serivce } \\
\text { (years) }\end{array}$ & $\begin{array}{c}\text { Time in service } \\
\text { at deployment } \\
\text { (years) }\end{array}$ \\
\hline 1 & 3 & 12 & 28 & 22 & 11 & 2 \\
\hline 2 & 4 & 11 & 33 & 31 & 13 & 11 \\
\hline 3 & 3 & 11 & 32 & 27 & 13 & 8 \\
\hline 4 & 4 & 9 & 33 & 32 & 12 & 11 \\
\hline 5 & 2 & 16 & 44 & 36 & 22 & 14 \\
\hline 6 & 6 & 9 & 26 & 26 & 10 & 9 \\
\hline 7 & 1 & 16 & 25 & 20 & 6 & 1 \\
\hline 8 & 1 & 11 & 26 & 24 & 4 & 2 \\
\hline 9 & 1 & 11 & 36 & 33 & 5 & 1 \\
\hline 10 & 1 & 15 & 32 & 23 & 9 & 1 \\
\hline 11 & 1 & 5 & 43 & 52 & 30 & 26 \\
\hline Mean & 2.454545455 & 11.45454545 & 32.54545455 & 30.6 & 12.27272727 & 7.818181818 \\
\hline SD & 1.694912173 & 3.297381882 & 6.455441679 & 8.846845012 & 7.66930126 & 7.73069443 \\
\hline
\end{tabular}

Table 4. Raw scores for each participant.

\begin{tabular}{|c|c|c|c|c|c|c|c|c|c|c|c|c|c|c|}
\hline Participant & $\begin{array}{l}\text { PCL } \\
\text { Score }\end{array}$ & $\begin{array}{c}\text { PTSD } \\
50+\end{array}$ & $\begin{array}{l}\text { PTSD } \\
\text { DSM }\end{array}$ & Both & $\begin{array}{c}\text { CD-RISC } \\
(0-100)\end{array}$ & $\begin{array}{c}\text { TRS } \\
\text { Total } \\
(0-145)\end{array}$ & $\begin{array}{c}\text { TRS } \\
\text { Shame } \\
(0-25)\end{array}$ & $\begin{array}{c}\text { Combat } \\
\text { Experiences } \\
(17-102)\end{array}$ & $\begin{array}{c}\text { Perceived } \\
\text { Threat } \\
(12-60)\end{array}$ & $\begin{array}{l}\text { Training } \\
\text { and } \\
\text { Deploymen } \\
\text { Prep. } \\
(10-50)\end{array}$ & $\begin{array}{l}\text { Deployment } \\
\text { Support } \\
\text { from Family } \\
\text { and Friends } \\
\quad(8-40)\end{array}$ & $\begin{array}{c}\text { Unit } \\
\text { Social } \\
\text { Support } \\
(11-55)\end{array}$ & $\begin{array}{l}\text { Concern } \\
\text { about } \\
\text { Family } \\
\text { Life and } \\
\text { Disruption } \\
(15-60)\end{array}$ & $\begin{array}{c}\text { Post- } \\
\text { Deployment } \\
\text { Social } \\
\text { Support } \\
(10-50)\end{array}$ \\
\hline 1 & 13 & $\mathrm{~N}$ & $\mathrm{~N}$ & $\mathrm{~N}$ & 58 & 104 & 19 & 72 & 42 & 37 & 24 & 55 & 36 & 32 \\
\hline 2 & 0 & $\mathrm{~N}$ & $\mathrm{~N}$ & $\mathrm{~N}$ & 94 & 73 & 16 & 32 & 18 & 48 & 32 & 45 & 43 & 35 \\
\hline 3 & 11 & $\mathrm{~N}$ & $\mathrm{~N}$ & $\mathrm{~N}$ & 88 & 75 & 13 & 70 & 39 & 41 & 38 & 38 & 33 & 47 \\
\hline 4 & 18 & $\mathrm{~N}$ & $\mathrm{Y}$ & $\mathrm{N}$ & 55 & 67 & 11 & 23 & 31 & 24 & 30 & 40 & 40 & 40 \\
\hline 5 & 19 & $\mathrm{~N}$ & Y & $\mathrm{N}$ & 83 & 64 & 12 & 37 & 37 & 40 & 31 & 43 & 30 & 39 \\
\hline 6 & 10 & $\mathrm{~N}$ & $\mathrm{~N}$ & $\mathrm{~N}$ & 88 & 87 & 17 & 44 & 16 & 50 & 40 & 55 & 26 & 47 \\
\hline Mean & 11.833 & 0 & $33 \%$ & 0 & 77.667 & 78.333 & 14.667 & 46.333 & 30.500 & 40.000 & 32.500 & 46.000 & 34.667 & 40.000 \\
\hline SD & 6.853 & & & & 16.789 & 14.881 & 3.141 & 20.304 & 11.077 & 9.274 & 5.788 & 7.376 & 6.314 & 6.132 \\
\hline 7 & 24 & $\mathrm{~N}$ & $\mathrm{Y}$ & $\mathrm{N}$ & 67 & 99 & 23 & 84 & 47 & 39 & 22 & 40 & 18 & 26 \\
\hline 8 & 21 & $\mathrm{~N}$ & $\mathrm{~N}$ & $\mathrm{~N}$ & 45 & 80 & 11 & 54 & 42 & 50 & 39 & 54 & 35 & 39 \\
\hline 9 & 2 & $\mathrm{~N}$ & $\mathrm{~N}$ & $\mathrm{~N}$ & 65 & 61 & 10 & 17 & 26 & 39 & 39 & 41 & 36 & 47 \\
\hline 10 & 0 & $\mathrm{~N}$ & $\mathrm{~N}$ & $\mathrm{~N}$ & 93 & 59 & 7 & 30 & 33 & 43 & 33 & 52 & 37 & 45 \\
\hline 11 & 1 & $\mathrm{~N}$ & $\mathrm{~N}$ & $\mathrm{~N}$ & 93 & 64 & 10 & 17 & 16 & 47 & 40 & 55 & 31 & 49 \\
\hline Mean & 9.600 & 0 & $20 \%$ & 0 & 72.600 & 72.600 & 12.200 & 40.400 & 32.800 & 43.600 & 34.600 & 48.400 & 31.400 & 41.200 \\
\hline SD & 11.844 & & & & 20.513 & 16.920 & 6.221 & 28.676 & 12.398 & 4.879 & 7.569 & 7.301 & 7.829 & 9.284 \\
\hline
\end{tabular}


Table 5. Descriptive statistics between component and survey results.

\begin{tabular}{cccccccc}
\hline T-Test Results & \multicolumn{2}{c}{ Active Duty } & \multicolumn{2}{c}{ NG/R } & & \\
\hline Factor & $\mathrm{M}$ & $\mathrm{SD}$ & $\mathrm{M}$ & $\mathrm{SD}$ & $t$ & $\mathrm{R}$-squared $(p<0.05)$ \\
CD-RISC & 77.66 & 16.79 & 72.60 & 20.51 & 0.44 & 0.02 \\
TRS Total & 78.33 & 14.88 & 72.61 & 16.92 & 0.59 & 0.04 \\
TRS Shame & 14.67 & 3.14 & 12.21 & 6.22 & 0.80 & 0.10 \\
Combat Experiences & 46.33 & 20.30 & 40.43 & 28.68 & 0.39 & 0.02 \\
Perceived Threat & 30.50 & 5.79 & 32.85 & 12.4 & 0.32 & 0.01 \\
Training & 40.00 & 9.27 & 43.62 & 4.88 & 0.82 & 0.08 \\
Deployment Support & 32.50 & 5.79 & 34.64 & 7.57 & 0.51 & 0.03 \\
Unit Cohesion & 46.00 & 7.38 & 48.40 & 7.30 & 0.54 & 0.03 \\
Concern about Family Life and Disruptions & 34.67 & 6.31 & 31.41 & 7.83 & 0.75 & 0.07 \\
Post-deployment Social Support & 40.00 & 6.13 & 41.23 & 9.28 & 0.25 & 0.01 \\
PCL Score & 11.83 & 6.85 & 9.60 & 11.84 & 0.46 & 0.02 \\
PTSD DSM & 0.33 & 0 & 0.20 & 0 & 0.46 & 0.02
\end{tabular}

Figure 1 displays the first round of linear regression analysis for AD. PCL Scores were compared to CD-RISC scores, TRS Total scores, and the subscale TRS shame scores. R-squared values for CD-RISC, TRS Total, and TRS Shame were $0.36,0.03$, and 0.26 respectively. There were no statistically significant correlations in this analysis.

Figure 2 displays the second round of linear regression analysis for AD. PCL Scores were compared to scores of the DRRI-2 subscales Combat Experiences, Perceived Threat, and Training. R-squared values for Combat Experiences, Perceived Threat, and Training were $0.001,0.37$, and 0.46 respectively. There were no statistically significant correlations in this analysis.

Figure 3 displays the second round of linear regression analysis for AD. PCL Scores were compared to scores of the DRRI-2 subscales Deployment Social Support, Unit Cohesion, Concern about Family Life and Disruption, and Post-deployment Social Support. R-squared values for Deployment Social Support, Unit Cohesion, Concern about Family Life and Disruption, and Post-deployment Social Support were 0.06, 0.03, 0.14, and 0.05 respectively. There were no statistically significant correlations in this analysis.

Figure 4 displays the first round of linear regression analysis for NG/R. PCL Scores were compared to CD-RISC scores, TRS Total scores, and the subscale TRS shame scores. R-squared values for CD-RISC, TRS Total, and TRS Shame were $0.53,0.89^{*}$, and 0.59 respectively. There was a statistically significant association found between the total TRS score and PCL scores $\left(\mathrm{R}^{2}=0.89\right)$. ${ }^{\star}$ Signifies statistically significant value.

Figure 5 displays the second round of linear regression analysis for NG/R. PCL Scores were compared to scores of the DRRI-2 subscales Combat Experiences, Perceived Threat, and Training. R-squared values for Combat Expe- 
riences, Perceived Threat, and Training were $0.86^{*}, 0.74$, and 0.006 respectively. There was a statistically significant association found between Combat Experiences and PCL scores $\left(\mathrm{R}^{2}=0.86\right)$. ${ }^{\star}$ Signifies statistically significant value.

Figure 6 displays the second round of linear regression analysis for NG/R. PCL Scores were compared to scores of the DRRI-2 subscales Deployment Social Support, Unit Cohesion, Concern about Family Life and Disruption, and Post-deployment Social Support. R-squared values for Deployment Social Support, Unit Cohesion, Concern about Family Life and Disruption, and Post-deployment Social Support were 0.30, 0.07, 0.40, and 0.79* respectively. There was a statistically significant association found between Post-deployment support and PCL scores $\left(\mathrm{R}^{2}=0.79\right) .{ }^{\star}$ Signifies statistically significant value.

AD 1-3

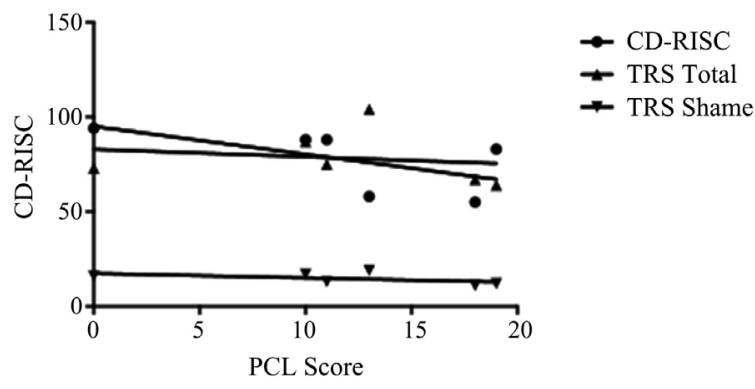

Figure 1. Linear regression of AD PCL scores with CD-RISC, TRS total, and TRS shame scores.

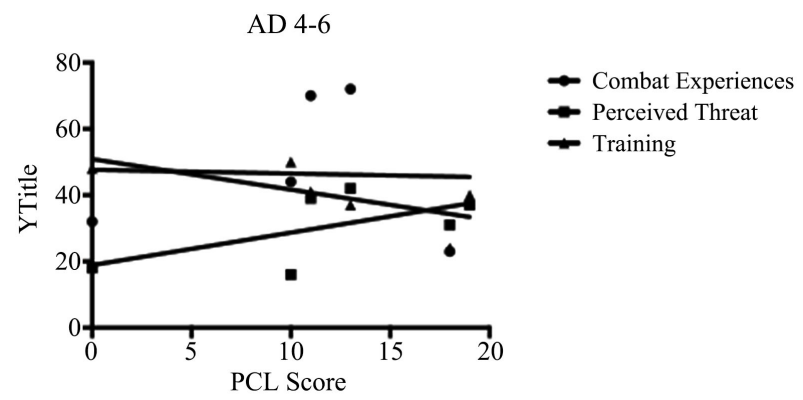

Figure 2. Linear regression of AD PCL scores with combat experiences, perceived threat, and training.

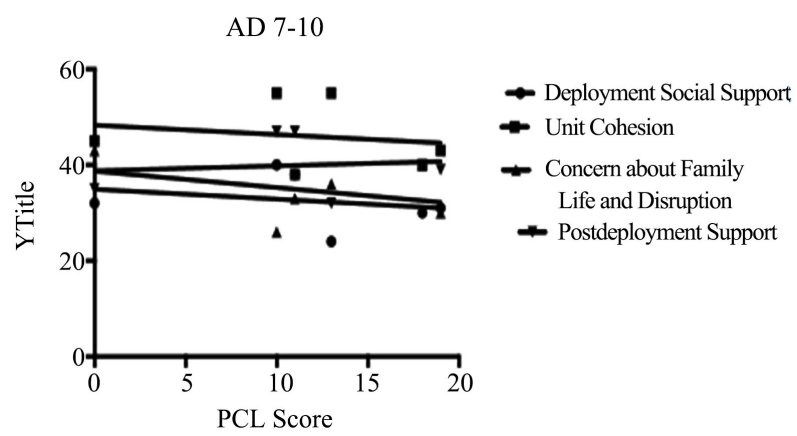

Figure 3. Linear regression of AD PCL scores with deployment social support, unit cohesion, concern about family life and disruption, and post-deployment social support. 
NG/R 1-3

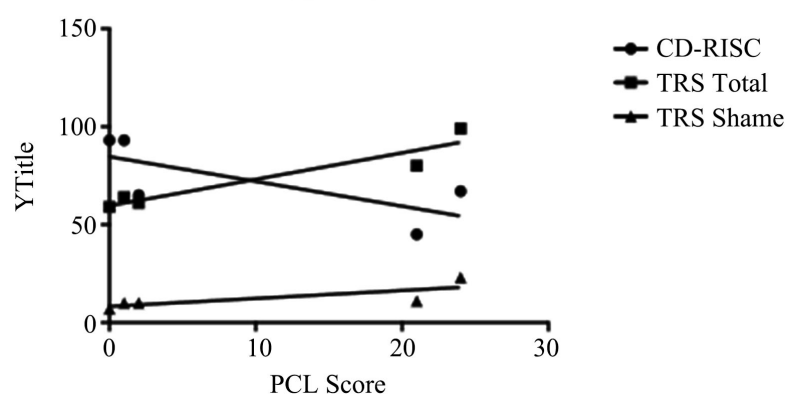

Figure 4. Linear regression of NG/R PCL scores with CD-RISC, TRS total, and TRS shame scores.

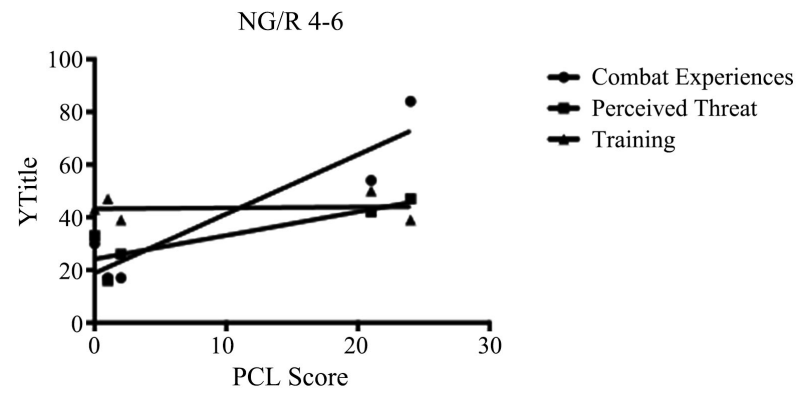

Figure 5. Linear regression of NG/R PCL scores with combat experiences, perceived threat, and training.

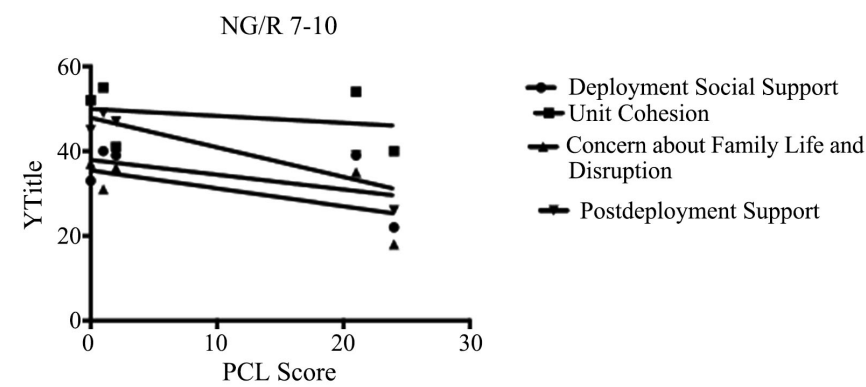

Figure 6. Linear regression of NG/R PCL scores with deployment social support, unit cohesion, concern about family life and disruption, and post-deployment social support.

All NG/R reported being deployed only once with an average length of deployment of $11.6 \pm 4.34$ months. The average number of deployments for $\mathrm{AD}$ was $3.67 \pm 1.37$ with an average length of the deployment of $11.33 \pm 2.58$ months. Overall, the entire population had deployed on average $2.45 \pm$ times and for an average of $11.45 \pm$ months. The average current age of the entire population was $32.54 \pm 6.45$ years, with NG/R averaging $32.4 \pm 7.44$ years and AD averaging $32.67 \pm 6.25$ years. The average age at deployment for the entire population was $30.60 \pm 8.84$ years, with NG/R averaging $30.4 \pm 13.0$ years and $\mathrm{AD}$ averaging $29.0 \pm 4.98$ years. The average total time in service for the entire population was $12.27 \pm 7.66$ years, with NG/R averaging $10.8 \pm 10.89$ years and $\mathrm{AD}$ averaging $13.5 \pm 4.32$ years. The average time in service at the start of the deployment was 
$7.81 \pm 7.73$ years, with NG/R averaging $6.20 \pm 11.07$ years and $\mathrm{AD}$ averaging $9.17 \pm 4.07$ years.

There was too little data to perform multiple regression analysis in this study, which would have been useful in identifying multiple variables that effect PTSD prevalence independently (including military component).

\section{Summary of Results}

This study sought to identify risk factors that make Reserve Component Soldiers more vulnerable to PTSD in a sample of 11 Army Reserve Component and Active Duty Operation Enduring Freedom and Operation Iraqi Freedom veterans. Linear regression analysis comparing the PTSD Checklist for DSM-V and the Deployment Risk and Resilience Inventory subscales were performed. Statistical significance was found for combat experience $\left(R^{2}=0.86\right)$ and post-deployment support $\left(\mathrm{R}^{2}=0.79\right)$. No significant differences between the predictive factors for PTSD experienced by each component (Active Duty vs. National Guard/Reserve) before, during, and after combat deployments. 95\% confidence intervals were used for all tests with $p<0.05$.

\section{Discussion}

The current study assessed differences in self-reported PTSD prevalence rates and their associations with predictive factors between Active Duty and National Guard/Reserve veterans deployed after September $11^{\text {th }}, 2001$. The results did not support the first research hypothesis that the NG/R component would report higher prevalence rates. In this case, the null hypothesis was accepted, as there was no statistical association found between PTSD prevalence rates for each component. This indicates that NG/R and AD experience the same types of predictive factors for PTSD before, during, and after deployments.

More important to this research was the second hypothesis that there are predictive factors that could elucidate vulnerabilities among NG/R. Although NG/R did not have higher self-reported PTSD prevalence rates, there were specific predictive factors that correlated with higher PTSD related symptoms among this group when compared to AD. Thus, the null hypothesis was rejected and the research hypothesis was accepted. The predictive factors that were significantly correlated with PTSD related symptoms among NG/R included stigma for seeking psychological help $\left(\mathrm{R}^{2}=0.89\right)$, combat experiences $\left(\mathrm{R}^{2}=0.86\right)$, and post-deployment social support $\left(\mathrm{R}^{2}=0.79\right)$. These associations may show specific areas of vulnerability for PTSD unique to NG/R.

In addition, current literature shows higher prevalence estimates for combat veterans as a subgroup compared to the average population. Meta-analyses and critical reviews on the point prevalence of PTSD in combat veterans report prevalence rates from 4\% - 18\% (Gates et al., 2012; Richardson et al., 2010; Shiromani et al., 2009). In comparison, national estimates of PTSD point prevalence and lifetime prevalence are $6.3 \%$ and $7.3 \%$ respectively (Kilpatrick et al., 2013). 
A meta-analysis published in 2008 comparing over 2500 studies of PTSD indicated that previous exposure to trauma was not a significant predictor of the development of PTSD ( $r=0.17)$ (Ozer et al., 2008). Additionally, the analysis showed that experiencing prior trauma was more closely associated with PTSD when the trauma was noncombatant or not typically experienced in combat environments (Ozer et al., 2008). A prior history of psychological disorder is also assessed in the Ozer et al. meta-analysis. In general, having a prior psychological adjustment has a small effect on the development of PTSD $(r=0.17)$. Moreover, this relationship was more significant when the traumatic event involved interpersonal violence rather than combat exposure (Ozer et al., 2008). In contrast, individual resilience is considered an important factor contributing to that individual soldier's risk for combat-related PTSD (King et al., 1998; Pietrzak et al., 2010; Waysman, 2001).

Stigma for seeking psychological help is considered a barrier to care for PTSD patients and an important moderator for self-reported PTSD symptoms (Hoge et al., 2004; Iversen et al., 2008; Reger et al., 2013). It is reported that Soldiers who scored positive in a screening for mental health disorders were twice as likely as those who scored negative to be concerned about being stigmatized (Hoge et al., 2004;. This barrier to mental health care arises primarily for a Soldier's concern about how they will be perceived by the rest of their fellow comrades and leadership should they test positive for a psychological disorder. They often fear to lose their current classification, rank, or being transferred to another unit (Hoge et al., 2004). This fear of stigmatism is a major concern among mental health care providers as it often prevents Soldiers from seeking treatment, believing in the effectiveness of treatment, or reporting what they believe to be symptoms of mental disorders (Hoge et al., 2004; Reger et al., 2013). This stigma could potentially prevent service members from seeking treatment for mental disease, believing in effectiveness of treatment, or reporting symptoms of mental illness, as they fear it could stain their military careers. Military personnel deemed less than $100 \%$ for either mental health or somatic health reasons have found their careers cut short or limited in progression. Until there is a culture shift, it is unlikely that there will be a resolution to this potential bias. This association could be stronger among NG/R because they may not receive the same mental health education opportunities as $\mathrm{AD}$. They only train one weekend monthly and two weeks out of the summer as opposed to the daily training and education that AD receive (Vogt et al., 2008). Perhaps they simply do not have the time in their priority of tasks to learn more about the importance of mental health and seeking treatment and thus naturally develop stigma against it. More research is necessary in this area to determine ways to circumvent these negative connotations associated with mental health.

\subsection{PTSD in Society}

Post-traumatic Stress Disorder has a strong impact on society. According to the Center for Disease Control and World Health Organization, suicide is the 16th 
leading cause of death worldwide and 10th in the U.S. (CDC, 2008; WHO, 2008). Specifically, suicide rates in the Army have been increasing over recent years while the civilian suicide rates have remained stable (Nock et al., 2013). Suicide rates among military personnel have, historically, been lower than civilian rates but in 2005, shortly after the start of Operation Iraqi Freedom, the U.S. Army suicide trends began increasing (Nock et al., 2013). In 2008, the rate of suicide in the U.S. Army surpassed the civilian rate and has continued to rise since then (Nock et al., 2013). Correlational studies have found that the increase in the suicide rates of Army Soldiers is paralleled by increased rates of mental illness (Bachynski et al., 2012). One study reported that among anxiety disorders, PTSD is most strongly associated with suicidal behavior (Sareen, 2014). Additionally, those suffering from PTSD are more likely to struggle with interpersonal problems, parenting difficulties, and to experience reductions in household income (Sareen, 2014). Over $90 \%$ of PTSD patients have at least one additional comorbid disorder (Sareen, 2014). Most commonly these include major depressive disorder and alcohol abuse or dependence, which are also associated with increased risk of suicidal ideation (Chilcoat \& Breslau, 1998; Tanielian \& Jaycox, 2008). Divorce rates also increase in patients with PTSD, and children with parents suffering from PTSD have more emotional problems than the rest of America's youth (Jordan et al., 1992; Riggs et al., 1998; Tanielian \& Jaycox, 2008). It is clear that PTSD strongly impacts the military population by negatively affecting psychological functioning and quality of life (Milliken et al., 2007; Schnurr et al., 2009). According to the 2008 RAND Study, the economic cost of PTSD in soldiers involved in the Iraq and Afghanistan war increased from $\$ 4$ billion to $\$ 6$ billion over two years (Tanielian \& Jaycox, 2008). The prevalence of PTSD has continued to rise since these conflicts (Gates et al., 2012; Richardson et al., 2010; Shiromani et al., 2009). Without proper research into interventions or factors that reduce the risk of the disease, the cost of PTSD and its impact on society will continue to grow.

\subsection{National Guard/Reserve Risk vs. Active Duty Risk}

In addition to high combat time exposure and deployment rates, the current War on Terror is unique in that a larger percentage of NG/R Soldiers deployed compared to previous conflicts (Tanielian \& Jaycox, 2008). As of October 2008, $1,638,817$ total Soldiers were deployed in support of either OEF or OIF (Tanielian \& Jaycox, 2008). The Army provided the majority of this force from the NG/R Component, with $47 \%$ of all NG/R veterans followed by the Navy with 23\%, the Air Force with 20\%, and the Marine Corps with 10\% (USDVA, 2010). Studies show that the development of post-deployment PTSD or PTSD related behavior was reported higher among NG/R soldiers than AD Soldiers (Griffith, 2010; Hoge et al., 2006; Jacobson et al., 2008; Milliken et al., 2007).

NG/R units come from a professional and personal culture distinct from AD units. NG/R and $A D$ units differ greatly with respect to military training. While $\mathrm{AD}$ units hone their skills daily, the average NG/R unit trains only one weekend 
per month and two weeks out of the summer at Annual Training (Vogt et al., 2008). This distinction in training between the two components may contribute to a different effect of deployment stressors. For example, NG/R units may experience less separation time from family and loved ones than $\mathrm{AD}$ units, which could make them more vulnerable to experiencing stress from social support during and after deployments. Additionally NG/R soldiers may not feel as prepared for deployment roles as $\mathrm{AD}$ soldiers due to less time spent in training environments. This could put them at higher risk for factors like preparedness and perceived threat. It could also have a direct effect on unit cohesion as NG/R soldiers do not have the same time and opportunities to develop lasting strong bond relationships as AD soldiers. A 2008 analysis found that when comparing deployment stressors between NG/R and AD soldiers that concern about family life and disruption was higher among NG/R soldier than AD soldiers (Vogt et al., 2008). They also found that NG/R soldiers perceived higher threat than AD soldiers although they reported less significant combat experiences (Vogt et al., 2008). These differences may be indicative of factors that make NG/R more vulnerable to mental disorders like PTSD due to their different military training and lifestyle. In peace time, most NG/R soldiers live civilian lifestyles and are only separated from their families once per month and 2 weeks out of the year while AD soldiers often train overseas or experience short term oversea deployments. These findings suggest that these differences may make NG/R soldiers more vulnerable to mental health disorders as they are not as well prepared to be separated from family and friends (Vogt et al., 2008).

The correlation found between combat experiences and PTSD related symptoms among NG/R is consistent with the initial idea that because NG/R do not deploy as frequently as $\mathrm{AD}$ they may not be well equipped to cope with war zone experiences. It is important here to note that though there was not a statistically significant difference in combat experience scores found between NG/R and AD, the mean for $\mathrm{NG} / \mathrm{R}$ was lower than $\mathrm{AD}(\mathrm{X}=40.43$, and $\mathrm{X}=46.33$ respectively). Active Duty soldiers experienced higher levels of combat exposure and yet this group did not show a significant association with PTSD related symptoms. This could be a sign of the greater psychological impact of combat experience on $\mathrm{NG} / \mathrm{R}$ than $\mathrm{AD}$. This finding builds on the statistically significant mean differences between the numbers of times deployed for each component. AD having deployed more frequently, may build coping mechanisms overseas that NG/R do not have the opportunity to build with fewer deployments. Additionally, it worth noting the correlation between perceived threat and PTSD symptoms among NG/R. Though this correlation was not statistically significant it was still high $\left(R^{2}=0.74\right)$, and is also consistent with the idea that experiencing less training and deployment opportunities could make NG/R less equipped to perceiving danger during combat and ultimately more vulnerable to PTSD.

Multiple studies available comparing NG/R and AD soldier deployment stressors have focused on identifying differences on their post-deployment health. One study found that UK reservists experienced higher rates of physical 
symptoms related to post-deployment mental health impairments including alcoholism when compared to "regular soldiers" or AD Soldiers (Hotopf et al., 2006). Additionally, studies performed on Gulf War veterans found that NG/R experienced more symptoms of fatigue, alcohol abuse, and PTSD related symptoms (Persian Gulf Study Group, 1997; Stretch et al., 1996). More recent post 9/11 research comparing post-deployment mental health outcomes in NG/R and AD Soldiers have shown that symptoms related to PTSD were reported higher among the former; however, these studies did not assess for pre-deployment PTSD predictive factors (Griffith, 2010; Hoge et al., 2006; Jacobson et al., 2008; Milliken et al., 2007). There are clearly predictive factors for PTSD that may make NG/R more vulnerable to PTSD than AD soldiers (Iversen et al., 2008; James et al., 2013; King et al., 1995; Mansfield et al., 2011; Ozer et al., 2008; Pietrzak et al., 2010; Pietrzak \& Southwick, 2011; Renshaw, 2011). The need to analyze what factors may make this particular group of soldier more susceptible to the disease is evident based on previous research indicating that NG/R has higher prevalence rates for PTSD (Griffith, 2010; Hoge et al., 2006; Jacobson et al., 2008; Milliken et al., 2007).

Post-deployment social support and PTSD symptoms were also a significant correlation among NG/R. This is also consistent with the idea that because NG/R experience less time away from family and friends than AD, they are not as prepared to deal with the aftermath of this separation upon returning from deployment. Feeling emotionally and tangibly supported by family and friends after deployments could be an important factor to prevent the development of post-deployment PTSD. Deployments put a lot of stress on family and personal relationships for a soldier. Returning to "norm" after a deployment takes time and patience for all parties involved. Because NG/R does not experience this separation as often as $\mathrm{AD}$, they may not be able to readjust to life at home as easily. The aftermath of this stress could fuel symptoms of PTSD, making them more vulnerable to the disease.

\section{Conclusion}

PTSD Prevalence rates were similar between components, but several predictive factors were significantly correlated with PTSD for Reserve Component veterans. Despite previous research, the current findings did not indicate a difference in self-reported prevalence between Active Duty soldiers and National Guard/ Reserve soldiers. This study also found no significant differences between the predictive factors for PTSD experienced by each component before, during, and after combat deployments. The current findings do, however, indicate specific predictive factors for PTSD that may make National Guard/Reservists more vulnerable to the disease including stigma for psychological help, combat experiences, and post-deployment social support. According to the 2005 National Defense Authorization Act, operational employment of reserve components will continue to increase in the future as many units will conduct daily operations in support of OEF and OIF (USDVA, 2010). The need to examine explanations for why there is a difference in post-deployment development of PTSD between 
$\mathrm{NG} / \mathrm{R}$ and AD Soldiers is evident, as many of these veterans will continue to be exposed to combat. While many studies examine rates of PTSD or related symptoms, few correlate the variance between the components with possible indicators or predictive factors that may explain the discrepancy.

There are several limitations to this study that should be outlined for future research. First, the population size was very small $(\mathrm{n}<12)$. For all purposes of this pilot study, this population size was sufficient; however, in order to confirm the findings found here, a larger sample population should be used. This study also did not include women. Recent literature finds that women are at higher risk for PTSD than men, and therefore a larger sample size should include controls for female veterans (Vogt et al., 2008). Additionally, population demographics in this study did not include race, ethnicity, or education level. Including these in future studies may help reduce some degrees of potential bias (Ozer et al., 2008). Finally, the self-report nature of the survey tool used in this research may reflect response bias due to psychological distress.

Future research should focus on further exploring these vulnerabilities and expanding upon the population sample used in this study. The War on Terror has deployed more National Guard/Reserve forces than any other conflict to date (Tanielian \& Jaycox, 2008), and the United States will continue to deploy more of these units to support daily operations in the future (USDVA, 2010). With the rising military suicide and PTSD prevalence rate (Gates et al., 2012; Richardson et al., 2010; Nock et al., 2013; Sareen, 2014; Shiromani et al., 2009), future research should continue to explore the vulnerabilities to PTSD of this particular component.

\section{Ethics}

This study was performed in accordance with human ethics considerations approved by the Philadelphia College of Osteopathic Medicine Institutional Review Board Protocol \#H15-034X.

\section{Availability of Data}

Please contact author for data requests.

\section{Authors' Contributions}

The authors (SMP) and (MRB) are solely responsible for the content of this paper. The first author (SMP) conceived this project, wrote the first draft of the manuscript, conducted the surveys, performed the initial data analysis, edited, and approved the final version of the manuscript. The second author (MRB) performed the final data analysis, wrote the final draft of this manuscript, edited, and approved the final version of the manuscript.

\section{Acknowledgements}

Not applicable. 


\section{Conflicts of Interest}

The authors declare no conflicts of interest regarding the publication of this paper.

\section{References}

Bachynski, K. E., Canham-Chervak, M., Black, S. A., Dada, E. O., Millikan, A. M., \& Jones, B. H. (2012). Mental Health Risk Factors for Suicides in the US Army, 2007-8. Injury Prevention, 18, 405-412. https://doi.org/10.1136/injuryprev-2011-040112

Baiocchi, D. (2013). Measuring Army Deployments to Iraq and Afghanistan. Santa Monica, CA: RAND Corporation.

Bliese, P. D., Cutter, C. J., Niles, B. L., \& Krinsley, K. E. (2008). Validating the Primary Care Posttraumatic Stress Disorder Screen and the Posttraumatic Stress Disorder Checklist with Soldiers Returning from Combat. Journal of Consulting and Clinical Psychology, 76, 272-281. https://doi.org/10.1037/0022-006X.76.2.272

Campbell, R. J. (2009). Campbell's Psychiatric Dictionary: The Definitive Dictionary of Psychiatry (Vol. 9). Oxford, New York: Oxford University Press.

Centers for Disease Control (CDC) (2008). National for Health Statistics, National Vital Statistics System, 10 Leading Causes of Death by Age Group, United States.

Chilcoat, H. D., \& Breslau, N. (1998). Posttraumatic Stress Disorder and Drug Disorders: Testing Causal Pathways. Archives of General Psychiatry, 55, 913-917. https://doi.org/10.1001/archpsyc.55.10.913

Connor Jonathan, K. M. (2003). Development of a New Resilience Scale: The Connor-Davidson Resilience Scale (CD-RISC) (pp. 76). New York: John Wiley \& Sons, Inc. https://doi.org/10.1037/t06346-000

DSM-V (2013). American Psychiatric Association, Diagnostic and Statistical Manual of Mental Disorders (Vol. 5). Washington DC. https://doi.org/10.1176/appi.books.9780890425596

Friedman, M. (2013). Finalizing PTSD in DSM-5. Getting Here from There and Where to Go Next. Journal of Traumatic Stress, 26, 548-556. https://doi.org/10.1002/jts.21840

Gates, M. A., Holowka, D. M., Vasterling, J. J., Keane, T. M., Marx, B. P., \& Rosen, R. C. (2012). Posttraumatic Stress Disorder in Veterans and Military Personnel: Epidemiology, Screening, and Case Recognition. Psychological Services, 9, 361-382. https://doi.org/10.1037/a0027649

Griffith, J. (2010). Citizens Coping as Soldiers: A Review of Deployment Stress Symptoms among Reservists. Military Psychology, 22, 176-206. https://doi.org/10.1080/08995601003638967

Hoge, C. W., Auchterlonie, J. L., \& Milliken, C. S. (2006). Mental Health Problems, Use of Mental Health Services, and Attrition from Military Service after Returning from Deployment to Iraq or Afghanistan. JAMA: Journal of the American Medical Association, 295, 1023-1032. https://doi.org/10.1001/jama.295.9.1023

Hoge, C. W., Castro, C. A., Messer, S. C., McGurk, D., Cotting, D. I., \& Koffman, R. L. (2004). Combat Duty in Iraq and Afghanistan, Mental Health Problems, and Barriers to Care. New England Journal of Medicine, 351, 13-22.

https://doi.org/10.1056/NEJMoa040603

Hotopf, M. L., Hull, L., Fear, N. T., Browne, T., Horn, O., Iverson, A. et al. (2006). The Health of UK Military Personnel Who Deployed to the 2003 Iraq War: A Cohort Study. The Lancet, 367, 1731-1741. https://doi.org/10.1016/S0140-6736(06)68662-5 
Iversen, A. C., Fear, N. T., Ehlers, A., Hacker-Hughes, J., Hull, L. et al. (2008). Risk Factors for Post-Traumatic Stress Disorder among UK Armed Forces Personnel. Psychological Medicine, 38, 511-522. https://doi.org/10.1017/S0033291708002778

Jacobson, I. G., Ryan, M. A., Hooper, T. I., Smith, T. C., Amoroso, P. J., Boyko, E. J. et al. (2008) Alcohol Use and Alcohol-Related Problems before and after Military Combat Deployment. JAMA: Journal of the American Medical Association, 300, 663-675. https://doi.org/10.1001/jama.300.6.663

James, L. M. et al. (2013). Risk and Protective Factors Associated with Symptoms of Post-Traumatic Stress, Depression, and Alcohol Misuse in OEF/OIF Veterans. Military Medicine, 178, 159-165. https://doi.org/10.7205/MILMED-D-12-00282

Jordan, B. K., Maramr, C. R., Fairnak, J. A., Schlenger, W. E., Kulka, R. A. et al. (1992). Problems in Families of Male Vietnam Veterans with Posttraumatic Stress Disorder. Journal of Consulting and Clinical Psychology, 60, 916-926. https://doi.org/10.1037/0022-006X.60.6.916

Kang, H. K., \& Bullman, T. A. (2008). Risk of Suicide among US Veterans after Returning from the Iraq or Afghanistan War Zones. Journal of the American Medical Association, 300, 652-653. https://doi.org/10.1001/jama.300.6.652

Keen, S. M. et al. (2008). Psychometric Properties of PTSD Checklist in Sample of Male Veterans. Journal of Rehabilitation Research \& Development, 45, 465-474. https://doi.org/10.1682/JRRD.2007.09.0138

Kemp, J., \& Boassarte, R. (2012). Suicide Data Report, 2012. Department of Veteran Affairs Mental Health Services Suicide Prevention Program.

Kilpatrick, D. G., Resnick, H. S., Melanak, M. E., Miller, M. W., Keyes, K. M., \& Friedman, M. J. (2013). National Estimates of Exposure to Traumatic Events and PTSD Prevalence Using DSM-IV and DSM-5 Criteria (pp. 537-547). New York: John Wiley \& Sons, Inc. https://doi.org/10.1002/jts.21848

King, D. W., King, L. A., Gudanowski, D. M., \& Vreven, D. L. (1995). Alternative Representations of War Zone Stressors: Relationships to Posttraumatic Stress Disorder in Male and Female Vietnam Veterans. Journal of Abnormal Psychology, 104, 184-196. https://doi.org/10.1037/0021-843X.104.1.184

King, L. A., King, D. W., Fairbank, J. A., Keane, T. M., \& Adams, G. A. (1998). Resilience-Recovery Factors in Post-Traumatic Stress Disorder among Female and Male Vietnam Veterans: Hardiness, Postwar Social Support, and Additional Stressful Life Events. Journal of Personality and Social Psychology, 74, 420-434. https://doi.org/10.1037//0022-3514.74.2.420

King, L. A., King, D. W., Vogt, D. S., Knight, J., \& Samper, R. E. (2006). Deployment Risk and Resilience Inventory: A Collection of Measures for Studying Deployment-Related Experiences of Military Personnel and Veterans. Military Psychology, 18, 89-120. https://doi.org/10.1207/s15327876mp1802_1

Mansfield, A. J. et al. (2011). Suicidal or Self-Harming Ideation in Military Personnel Transitioning to Civilian Life. Suicide \& Life-Threatening Behavior, 41, 392-405. https://doi.org/10.1111/j.1943-278X.2011.00039.x

Milliken, C. S., Hoge, C. W., \& Auchterlonie, J. L. (2007). Longitudinal Assessment of Mental Health Problems among Active and Reserve Component Soldiers Returning from the Iraq War. Journal of the American Medical Association, 298, 2141-2148. https://doi.org/10.1001/jama.298.18.2141

Nock, M. K., Deming, C. A., Fullerton, C. S., Gilman, S. E., Goldenberg, M., Kessler, R. C. et al. (2013). Suicide among Soldiers: A Review of Psychosocial Risk and Protective Factors. Psychiatry: Interpersonal \& Biological Processes, 76, 97-125. 
https://doi.org/10.1521/psyc.2013.76.2.97

Ozer, E. J., Best, S. R., Lipsey, T. L., \& Weiss, D. S. (2008). Predictors of Posttraumatic Stress Disorder and Symptoms in Adults: A Meta-Analysis. Psychological Trauma: Theory, Research, Practice, and Policy, S, 3-36. https://doi.org/10.1037/1942-9681.S.1.3

Persian Gulf Study Group (1997). Self-Reported Illness and Health Status among Gulf War Veterans. A Population-Based Study. The Iowa Persian Gulf Study Group. JAMA: Journal of the American Medical Association, 277, 238-245.

Pietrzak, R. H., \& Southwick, S. M. (2011). Psychological Resilience in OEF-OIF Veterans: Application of a Novel Classification Approach and Examination of Demographic and Psychosocial Correlates. Journal of Affective Disorders, 133, 560-568.

https://doi.org/10.1016/j.jad.2011.04.028

Pietrzak, R. H., Johnson, D. C., Goldstein, M. B., Malley, J. C. et al. (2010). Psychosocial Buffers of Traumatic Stress, Depressive Symptoms, and Psychosocial Difficulties in Veterans of Operations Enduring Freedom and Iraqi Freedom: The Role of Resilience, Unit Support, and Postdeployment Social Support. Journal of Affective Disorders, 120, 188-192. https://doi.org/10.1016/j.jad.2009.04.015

Reger, G. M., Durham, T. L., Tarantino, K. A., Luxton, D. D., Holloway, K. M., \& Lee, J. A. (2013). Deployed Soldiers' Reactions to Exposure and Medication Treatments for PTSD. Psychological Trauma: Theory, Research, Practice, and Policy, 5, 309-316. https://doi.org/10.1037/a0028409

Renshaw, K. D. (2011). An Integrated Model of Risk and Protective Factors for Post-Deployment PTSD Symptoms in OEF/OIF Era Combat Veterans. Journal of Affective Disorders, 128, 321-326. https://doi.org/10.1016/j.jad.2010.07.022

Richardson, L. K., Frueh, B. C., \& Acierno, R. (2010). Prevalence Estimates of Combat-Related Post-Traumatic Stress Disorder: Critical Review. Australian \& New Zealand Journal of Psychiatry, 44, 4-19. https://doi.org/10.3109/00048670903393597

Riggs, D. S., Byrne, C. A., Weathers, F. W., \& Litz, B. T. (1998). The Quality of the Intimate Relationships of Male Vietnam Veterans: Problems Associated with Posttraumatic Stress Disorder. Journal of Traumatic Stress, 11, 87-101. https://doi.org/10.1023/A:1024409200155

Sareen, J. (2014). Posttraumatic Stress Disorder in Adults: Impact, Comorbidity, Risk Factors, and Treatment. Canadian Journal of Psychiatry, 59, 460-467. https://doi.org/10.1177/070674371405900902

Schnurr, P. P., Lunney, C. A., Bovin, M. J., \& Marx, B. P. (2009). Posttraumatic Stress Disorder and Quality of Life: Extension of Findings to Veterans of the Wars in Iraq and Afghanistan. Clinical Psychology Review, 29, 727-735. https://doi.org/10.1016/j.cpr.2009.08.006

Shiromani, P. J., Keane, T. M., \& LeDoux, J. E. (2009). Post-Traumatic Stress Disorder, Basic Science and Clinical Practice. New York: Humana Press.

Stretch, R. H., Marlowe, D. H., Wright, K. M., Bliese, P. D., Knudson, K. H., \& Hoover, C. H. (1996). Post-Traumatic Stress Disorder Symptoms among Gulf War Veterans. Military Medicine, 161, 407-410. https://doi.org/10.1093/milmed/161.7.407

Tanielian, T., \& Jaycox, L. H. (2008). Invisible Wounds of War: Psychological and Cognitive Injuries, their Consequences, and Services to Assist Recovery. Santa Monica, CA: RAND Corporation. https://doi.org/10.1037/e527612010-001

Tsai, J., Harpaz-Rotem, I., Pietrzak, R. H., \& Southwick, S. M. (2012). The Role of Coping, Resilience, and Social Support in Mediating the Relation between PTSD and Social Functioning in Veterans Returning from Iraq and Afghanistan. Psychiatry: Interper- 
sonal \& Biological Processes, 75, 135-149.

https://doi.org/10.1521/psyc.2012.75.2.135

USDVA (2010). United States Department of Veterans Affairs, National Survey of Veterans Active Duty Service Members, Demobilized National Guard and Reserve Members, Family Members, and Surviving Spouses. Final Report, Washington DC: Department of Veterans Affairs.

Vogt, D. S. B. N. K. D. W. and King, L. A. (2012). Manual for the Deployment Risk and Resilience Inventory-2 (DRRI-2): A Collection of Measures for Studying Deployment-Related Experiences of Military Veterans. Boston, MA: National Center for PTSD.

Vogt, D. S., Sampler, R. E., King, D. W., King, L. A., \& Martin, J. A. (2008). Deployment Stressors and Posttraumatic Stress Symptomatology: Comparing Active Duty and National Guard/Reserve Personnel from Gulf War I. Journal of Traumatic Stress, 21, 66-74. https://doi.org/10.1002/jts.20306

Waysman, M. J. Z. (2001). Hardiness: An Examination of Its Relationship with Positive and Negative Long Term Changes Following Trauma. Journal of Traumatic Stress, 14, 531-548. https://doi.org/10.1023/A:1011112723704

WHO (2008). The Global Burden of Disease: 2004 Update. 